$10 / 18.948 .80$

SANDIA REPORT

SAND93-1076 • Revised • UC-\$06

Unlimited Release

Printed September 1994

\title{
Standard Testing Procedures for Optical Fiber and Unshielded Twisted Pair at Sandia National Laboratories
}

\author{
R. L. Adams
}

Prepared by

Sandia National Laboratories

Albuquerque, New Mexico 87185 and Livermore, California 94550

for the United States Department of Energy

under Contract DE-AC04-94AL85000

Supersedes SAND93-1076 dated November 1993

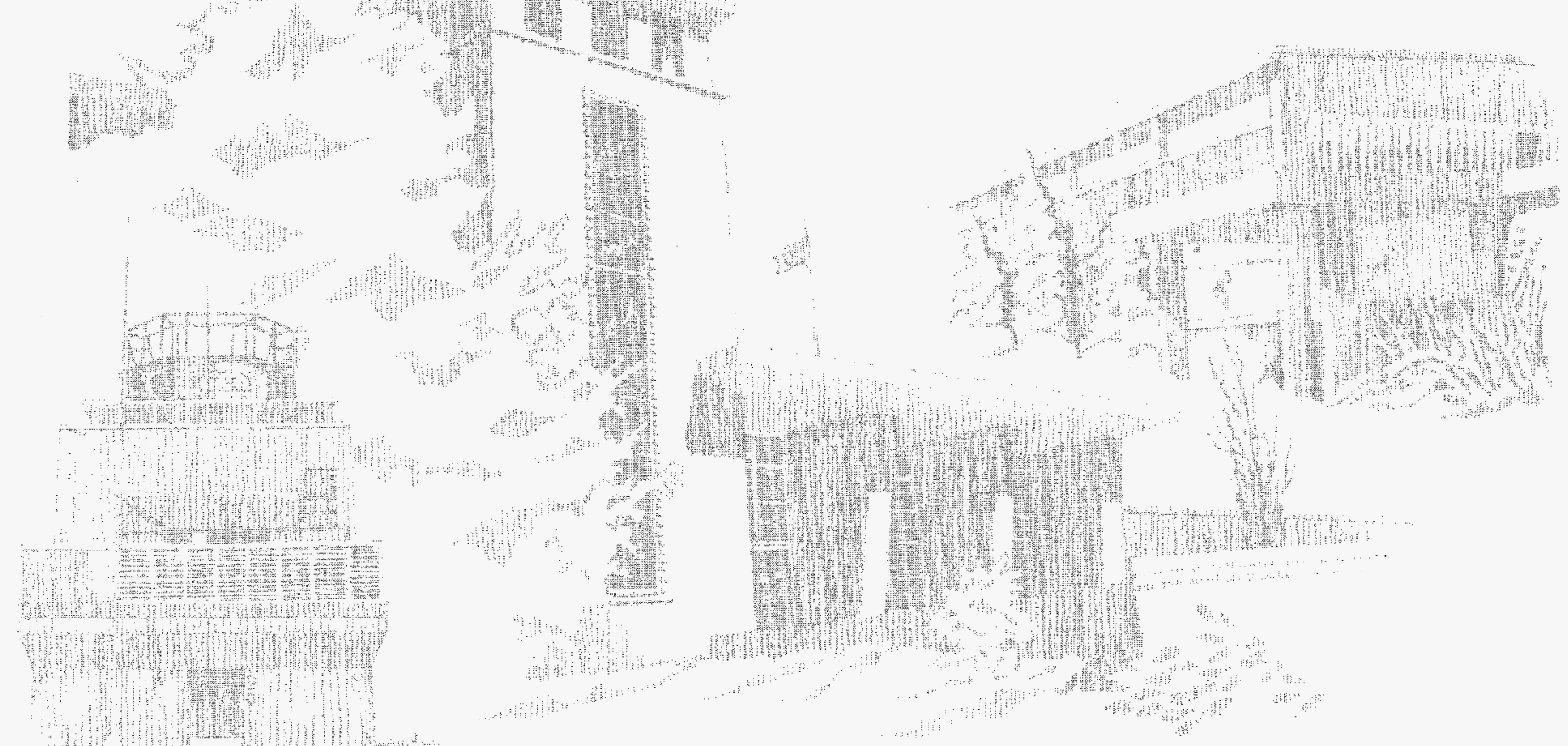


Issued by Sandia National Laboratories, operated for the United States Department of Energy by Sandia Corporation.

NOTICE: This report was prepared as an account of work sponsored by an agency of the United States Government. Neither the United States Government nor any agency thereof, nor any of their employees, nor any of their contractors, subcontractors, or their employees, makes any warranty, express or implied, or assumes any legal liability or responsibility for the accuracy, completeness, or usefulness of any information, apparatus, product, or process disclosed, or represents that its use would not infringe privately owned rights. Reference herein to any specific commercial product, process, or service by trade name, trademark, manufacturer, or otherwise, does not necessarily constitute or imply its endorsement, recommendation, or favoring by the United States Government, any agency thereof or any of their contractors or subcontractors. The views and opinions expressed herein do not necessarily state or reflect those of the United States Government, any agency thereof or any of their contractors.

Printed in the United States of America. This report has been reproduced directly from the best available copy.

Available to DOE and DOE contractors from Office of Scientific and Technical Information

PO Box 62

Oak Ridge, TN 37831

Prices available from (615) 576-8401, FTS 626-8401

Available to the public from

National Technical Information Service

US Department of Commerce

5285 Port Royal Rd

Springfield, VA 22161

NTIS price codes

Printed copy: A03

Microfiche copy: A01 


\section{DISCLAIMER}

Portions of this document may be illegible in electronic image products. Images are produced from the best available original document. 


\title{
Standard Testing Procedures for Optical Fiber and Unshielded Twisted Pair at Sandia National Laboratories
}

\author{
R. L. Adams \\ Communications Department \\ Sandia National Laboratories \\ Albuquerque, NM 87185-5800
}

\begin{abstract}
This revision updates Sandia's working standard for testing optical fiber and unshielded twisted pair cables included in the Lab-wide telecommunications cabling infrastructure. The purpose of these standard testing procedures is to deliver to all Sandians a reliable, low-maintenance, state-of-the-art, ubiquitous telecommunications cabling infrastructure capable of satisfying all current and future telecommunication needs.
\end{abstract}




\section{Acknowledgments}

I would like to thank Jon A. Eberhart of Holmes and Narver Inc. His assistance in formalizing the information contained in the original document, especially in the section entitled "Unshielded Twisted Pair," was greatly appreciated.

I would like to thank James J. Refi of AT\&T Network Systems for sharing his knowledge and insight pertaining to the as yet ill-defined intrabuilding cabling issue, optical reflectance.

I would like to thank Kelvin B. Bradley of AT\&T Network Systems for sharing his knowledge and assistance in resolving several critical connector performance issues which arose in the field.

I would like to express a sincere thanks to Bob Dougherty, Dept. 13902, for being the Recabling Project's "essential enabler." Bob's wisdom and vision allowed him to identify the modernization of Sandia's entire telecommunications infrastructure as a critical survival task facing Sandia National Laboratories. Bob possesses a truly remarkable suite of personal skills and inner motivation. It is a true joy to work with an individual of Bob's caliber. Keep it up Bob!

Lastly, I would like to thank Mary Elizabeth Stevenson-Adams for her continuous support and love. Mary's gifts of grace and compassion have allowed me to experience fulfillment both at work and more importantly, at home. 


\section{Contents}

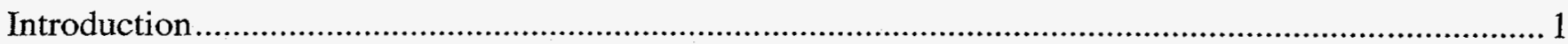

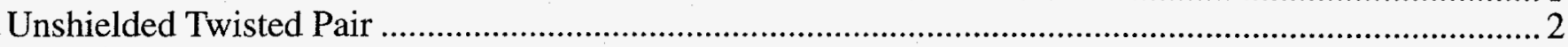

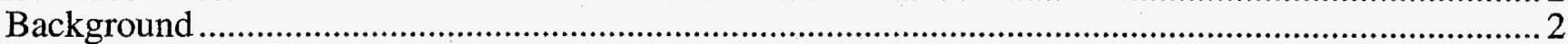

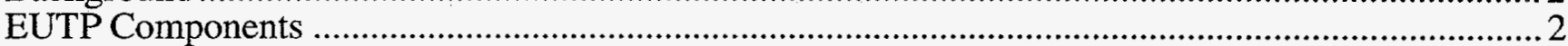

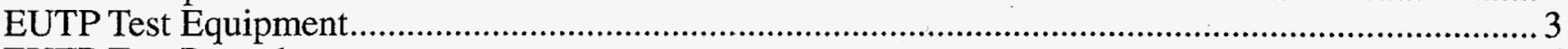

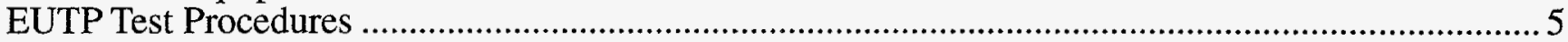

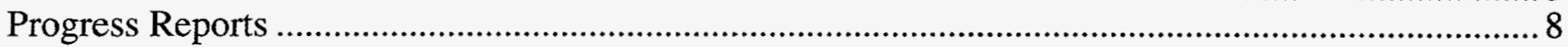

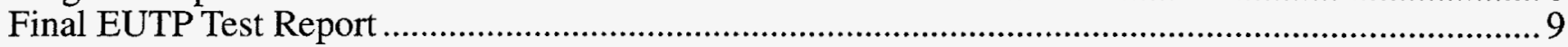

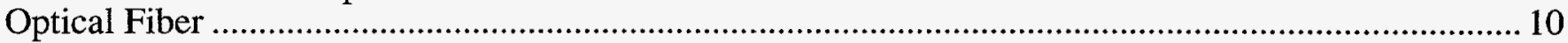

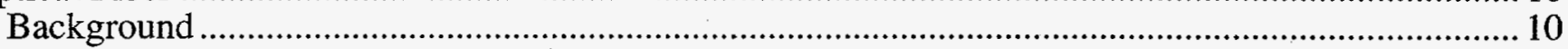

Optical Fiber Components ........................................................................................... 10

Optical Fiber Test Equipment ..................................................................................... 11

Optical Fiber Test Procedures ....................................................................................... 12

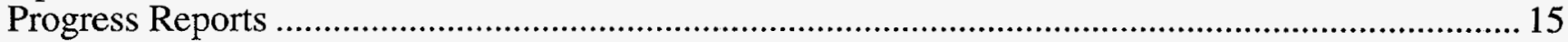

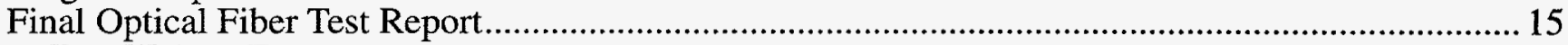

APPENDIX A — Form ..................................................................................................... 17

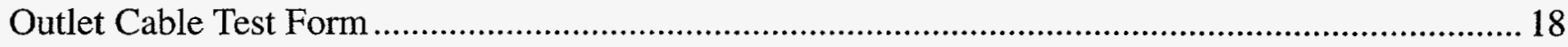

Table

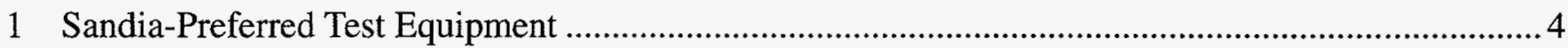




\section{Preface}

Since the early 1980s, the Communications Department has been installing optical fiber and unshielded twisted pair cables to support the secure data communications network. In 1993, a major building recabling project was initiated at Sandia National Laboratories, New Mexico. This project consists of massive intrabuilding telecommunication cable installations comprised of both optical fiber and unshielded twisted pair cables. The standard testing procedures contained in this document were created in support of Sandia's extensive Recabling Project.

This document defines standard testing procedures for optical fiber cables (both Multimode and Singlemode) and enhanced unshielded twisted pair cables. Adherence to these testing procedures will ensure a standard high-quality transmission capability throughout Sandia's entire telecommunications infrastructure.

This document requires manufacturer-recommended, hardware-specific installation and termination procedures to be performed on associated components. Creating a Lab-wide, high-quality standard telecommunications cabling infrastructure will greatly contribute to Sandia's ability to remain one of the premiere high-technology research and development centers in the world. 


\section{Acronyms}

10BaseF $10 \mathrm{Mbps}$ baseband optical fiber media

10Base $\mathrm{T} \quad 10 \mathrm{Mbps}$ baseband twisted pair media

$\mathrm{AC}$

alternating current

ANSI

ATM

AT\&T

$\mathrm{dB}$

$\mathrm{dBm}$

DC

$\mathrm{CaA}$

$\mathrm{CaL}$

$\mathrm{CoA}$

$\mathrm{CoQ}$

DC

EIA/TIA

EMI

American National Standards Institute

asynchronous transfer mode

American Telephone and Telegraph

decibel

decibels referenced to a milliwatt

direct current

cable attenuation in $\mathrm{dB} / \mathrm{km}$

cable length in kilometers

connector attenuation in $\mathrm{dB}$

connector quantity

ESCON®

EUTP

FDDI

$\mathrm{ft}$

$\mathrm{GHz}$

$\mathrm{HIGH}-5^{\mathrm{TM}}$

$\mathrm{Hz}$

IDR

IEEE

$\mathrm{KHz}$

$\mathrm{km}$

LA

direct current

Electronic Industries Association/Telecommunications Industry Association

electromagnetic interference

registered trademark of IBM, Enterprise Systems Connection

enhanced unshielded twisted pair

fiber distributed data interface

feet

gigahertz, one billion cycles per second

registered trademark of AT\&T, designates hardware capable of $155 \mathrm{Mbps}$ data rates

Hertz, frequency in cycles per second

intermediate distribution room

Institute of Electrical and Electronics Engineers

kilohertz, one thousand cycles per second

kilometer, one thousand meters

LASER

LRL

Mbps

$\mathrm{MHz}$

MM

$\mathrm{mV}$

$\mathrm{mW}$

NEXT

nf

$\mathrm{nm}$

NVP

OTDR

RFI

RJ

link attenuation

opto-electronic device which emits coherent light

link return loss

megabps, one million bits per second

megahertz, one million cycles per second

Multimode (optical fiber)

millivolts, one thousandth of a volt

milliwatt, one thousandth of a Watt

near-end cross-talk

nanofarad, one billionth of a farad (capacitance)

nanometer, one billionth of a meter

nominal velocity of propagation

optical time domain reflectometer

radio frequency interference

registered jack

SM

SNR

Singlemode (optical fiber)

SONET

signal-to-noise ratio

ST®

synchronous optical network

registered trademark of AT\&T, straight tip (optical connector) 
registered trademark of AT\&T, straight tip version 2 (optical connector)

TDR time domain reflectometer

$\mathrm{THz}$

TV

terahertz, one trillion cycles per second

UTP

television

unshielded twisted pair

VAR

value added reseller 


\section{Standard Testing Procedures for Optical Fiber and Unshielded Twisted Pair at Sandia National Laboratories}

\section{Introduction}

Past telecommunications cabling distribution systems at Sandia National Laboratories were designed and installed to meet simple transmission requirements. Voice and data transmissions typically required frequencies in the low kilohertz $(\mathrm{KHz})$ range. Today's technologies require frequencies in the megahertz $(\mathrm{MHz})$ range, and are rapidly approaching the gigahertz $(\mathrm{GHz})$ range. New cable infrastructures must be installed to meet these expanding bitrate demands.

The capabilities of a modern cable infrastructure are primarily dependant on component quality and cable installation and termination procedures.

Components include cables, connectors, and couplers. Sandia required high-quality components are specified in SAND93-0002 Revised, Intra-Building Telecommunications Cabling Standard for Sandia National Laboratories. Maximum performance of these components can only be realized by proper installation and termination procedures. When installed and assembled, the components function as a single integrated unit or communication path.

All cable installation at Sandia must follow manufacturer-recommended installation procedures. Improper cable installation can drastically degrade the cable infrastructure capabilities by adding random inconsistencies such as frequency or bandwidth variations and attenuation or loss. All AT\&T cable installations at Sandia must follow procedures described in AT\&T's SYSTIMAX Premises Distribution System Installation Guidelines documents.

All cable termination at Sandia must follow manufacturer-recommended termination procedures. These procedures, along with testing and labeling, will be incorporated in a standard Sandia Facilities Engineering document written in Construction Specification Institute format. This document is currently being developed. It must then be approved by the Facilities Standards Committee prior to formal issue as Standard Specification Section 16796 Telecommunication Cable Termination, Testing, and Labeling. In future telecommunication construction activities, Section 16796 will be issued with each Universal Construction Package.

Cable termination requires many sophisticated mechanical assembly techniques and the use of high-precision tools and test equipment. As with improper installation, improper termination techniques can also drastically degrade the cable infrastructure capabilities. For example, improper terminations can result in unacceptable attenuation and reflections. The investment in high-quality components will be lost if termination procedures are not performed in a standard repeated method.

It is therefore absolutely necessary to adhere to the specific test procedures defined in this document to ensure ubiquitous capability, compatibility, expandability, reliability, and functionality throughout Sandia's telecommunications cabling infrastructure. 


\section{Unshielded Twisted Pair}

\section{Background}

Before the advent of optical fiber, copper conductors were the prime choice for communications cabling. Even though better conducting materials were available (such as gold), copper provided the best balance between good conductance, cost, and material availability.

Today's technology allows data to be transmitted on special unshielded twisted pair (UTP) copper lines at hundreds of Mbps (million bits per second). At these speeds, all the information contained in an entire set of encyclopedias could be transmitted in tens of seconds! This special type of UTP is referred to as enhanced UTP, or abbreviated as EUTP. High-speed data capability over EUTP does not come easily. Required are high-purity copper, precision twisting of the wire pairs, careful installation, matched precision components, and very sophisticated (and costly) transmission encoding and decoding electronics. The 100-meter (or approximately 300-foot) length limitation imposed on EUTP is derived from the American National Standards Institute (ANSI) Electronic Industries Association/ Telecommunications Industry Association (EIA/TIA) Building Telecommunication Wiring Standard document 568A. *At this length, EUTP is an excellent transmission media for intra-building cabling.

In spite of new high-speed EUTP systems, optical fiber is still the preferred transmission media for future communications systems. When compared to high-speed EUTP systems, optical fiber can deliver even greater quantities of bits, transmit over longer distances, and provide more immunity to external sources of interference. However, the new high-speed EUTP cable remains extremely useful for several reasons:

*NOTE: This Sandia document was written and published prior to the official release of ANSI EIAV TIA 568A.
- EUTP cabling is still convenient for use with existing copper-based equipment.

- EUTP speeds are often satisfactory for systems that do not require massive quantities of data transfer.

- EUTP is still more cost effective for short runs due to the relatively higher cost of optical fiber connectors and terminations. Testing costs between EUTP and optical fibers is a current area of debate.

- EUTP cabling and electronic components are currently less expensive than comparable opto-electronic components, although the trend over the past 10 years has brought both costs much closer together.

\section{EUTP Components}

EUTP components utilized at Sandia National Laboratories include twisted-pair copper cables, connectors, mass termination frames and blocks, outlets, patch panels, cross-connect jumpers, and splices. These components are further described and specified in SAND93-0002 Revised, Intra-Building Telecommunications Cabling Standard for Sandia National Laboratories. This document can be obtained by contacting Sandia Department 13917.

AT\&T recently demonstrated the capability of their state-of-the-art HIGH-5 ${ }^{\text {TM }}$ EUTP product line. An unprecedented transmission rate of $622 \mathrm{Mbps}$ was achieved. This extraordinary EUTP product line capability, being completely superior to all other manufacturers' EUTP products available today, is the basis for Sandia's AT\&T HIGH-5 ${ }^{\mathrm{TM}}$ EUTP product line sole-make requirement. Additionally, these products, when installed by an AT\&T certified value added reseller (VAR), are currently guaranteed to deliver up to $155 \mathrm{Mbps}$ data rates and warranted for 15 years.

The following are general descriptions of each EUTP component.

\section{EUTP Cables}

EUTP cables for high-speed applications may appear similar to regular telephone cables, but are in fact quite different. EUTP cables are made of high-purity copper, have special preci- 
sion pair twisting, and use special jacketing materials. Specialized installation procedures are also required as these cables are sensitive to bending, kinking, and overstressing.

Pair twisting is a critical parameter. In a four-pair EUTP cable, each pair has a different twist ratio. This not only reduces crosstalk (signal coupling) between the two conductors of a pair, but also minimizes crosstalk between adjacent pairs within a cable.

All EUTP cabling at Sandia must be AT\&T HIGH-5 ${ }^{\text {TM }}$ EUTP to provide maximum capability and reliability for years to come.

\section{EUTP Connectors}

EUTP connectors must match the EUTP cable's transmission capability.

All EUTP connectors at Sandia must be AT\&T HIGH-5 ${ }^{\text {TM }}$ RJ45 modular jacks with T568A pin configurations as described in EIA/ TIA-568A.

\section{EUTP Mass Termination Frames and Blocks}

The intermediate distribution room (IDR) EUTP mass termination frames and blocks must match the EUTP cable's transmission capability and accommodate an extremely large number of cables and conductors. AT\&T 110 mass termination frames and blocks allow extremely dense termination of EUTP conductors. A typical 110 mass termination frame is capable of terminating 3600 wire pairs. AT\&T 110 termination blocks provide consistent, reliable, repeatable, gas-tight connections for data, voice, or any other low-voltage circuit.

All EUTP mass termination frames and blocks at Sandia must be AT\&T HIGH-5 ${ }^{\text {TM }} 110$ frames and blocks.

\section{EUTP Outlets}

Sandia's standard outlet is shown in SAND93-0002 Revised. The outlet is commonly referred to as a multimedia outlet because it houses both EUTP and optical fiber cables. AT\&T's original $40 \mathrm{~A} 1$ outlet was specifically modified to accommodate Sandia's standard cable suite and red and black color requirements.

All outlets at Sandia must be AT\&T 40A1 components.

\section{EUTP Patch Panels and Cross-Connect Jump- ers}

EUTP patch panels and cross-connect jumpers must also match the EUTP cable's transmission capability.

ALL EUTP patch panels and cross-connect jumpers must be AT\&T HIGH-5 ${ }^{\mathrm{TM}}$ products incorporating RJ45 modular jacks with T568A pin configurations as described in EIA/TIA-568A.

\section{EUTP Splicing}

At Sandia, UTP splicing has been used for cable-cut emergency restoration, but is not a part of normal cable installation.

Splicing is not permitted in any intrabuilding EUTP cabling and will not be discussed in this document due to its limited application. Any cabling issues concerning EUTP splicing must be brought to the attention of Sandia Dept. 13917 personnel for consideration and approval.

\section{EUTP Test Equipment}

There are eight basic types of test equipment used to verify installed EUTP link transmission capabilities. They are

- ohmmeter

- terminators

- time domain reflectometer (TDR)

- noise meter

- line mapper

- high-frequency signal generator

- capacitance meter

- power meter

\section{Ohmmeter}

The function of an ohmmeter is often included as part of a multimeter or volt-ohmmilliammeter. It is typically used to measure continuity of a conductor by testing for a short circuit or a known resistance applied across the opposite end of the conductor. Although ohmmeters are commonly used to validate coaxial cabling systems, they alone are not sufficient to validate EUTP cabling systems. 


\section{Terminators}

Terminators end a cable segment under test by providing either a short circuit or several known resistances for matching wire pairs. Shorting terminators may not detect shorts due to cable damage. Impedance-matching terminators provide more reliable test information because they closely approximate actual system working conditions. Intelligent terminators contain on-board circuitry and can transmit and receive to work in conjunction with a handheld test set.

\section{Time Domain Reflectometer (TDR)}

A TDR is used to determine cable length and locations of impedance mismatch. It transmits a fast rise-time pulse down a copper conductor and then monitors for pulse reflections. Impedance mismatches cause electrical reflections which can be displayed on an oscilloscope-like screen or a numerical display. While most defects cause minor reflections, the end of a conductor (or a break) produces a major reflection. The cable's length or the location of a defect may be calculated by combining a pulse reflection's travel time with the conductor's nominal velocity of propagation (NVP). NVP is typically a fractional value of the speed of light and is provided by the cable manufacturer.

\section{Noise Meter}

A wide-band $\mathrm{AC}$ noise meter can detect problems from electromagnetic interference (EMI) and radio frequency interference (RFI) by measuring the strengths of unwanted signals and analyzing the frequencies of induced line noise, thereby aiding in the identification of the noise sources. Although shielded cable is less susceptible to line noise than EUTP cable, properly twisted EUTP cable can provide reliable high-speed data transmissions at a lower cost. Installing the EUTP cables in a grounded metallic conduit can further reduce the cable's vulnerability to electronic disturbances. However,

\section{Table 1. Sandia-Preferred Test Equipment (September 1994)}

\begin{tabular}{|c|c|c|c|}
\hline Equipment & Manufacturer & Model & Description \\
\hline \multirow[t]{2}{*}{$\begin{array}{l}\text { Optical Loss/ } \\
\text { Return Loss } \\
\text { Test Set }\end{array}$} & EXFO & $\begin{array}{l}\text { FOT-913-12D-32 } \\
\text { - Multimode }\end{array}$ & $\begin{array}{l}\text { Dual Wavelength } 850 / 1300 \mathrm{~nm} \text { LED } \\
\text { source with } S T \circledast \text { connector and } \\
\text { InGaAs detector }\end{array}$ \\
\hline & TTC & $\begin{array}{l}\text { 462L } \\
\text { - Singlemode }\end{array}$ & $\begin{array}{l}\text { Dual Wavelength } 1310 / 1550 \mathrm{~nm} \\
\text { Cooler LASER with HRL faceplate } \\
\text { connector and InGaAs detector }\end{array}$ \\
\hline \multirow[t]{3}{*}{ OTDR } & TEKTRONICS & TFP2 FiberMaster & \\
\hline & & $\begin{array}{l}\text { FM8513-Option } 24 \\
\text { - Multimode }\end{array}$ & $\begin{array}{l}\text { Dual Wavelength } 850 / 1300 \mathrm{~nm} \\
\text { source with } \mathrm{ST} \otimes \mathrm{PC} \text { connector }\end{array}$ \\
\hline & & $\begin{array}{l}\text { FM1315-Option } 34 \\
\text { - Singlemode }\end{array}$ & $\begin{array}{l}\text { Dual Wavelength } 1310 / 1550 \mathrm{~nm} \\
\text { source with ST® PC connector }\end{array}$ \\
\hline $\begin{array}{l}\text { Optical } \\
\text { Interferometer }\end{array}$ & $\begin{array}{l}\text { Norland Products } \\
\text { Inc. }\end{array}$ & Connect-Chek & $\begin{array}{l}\text { Portable/bench video microscope } \\
\text { with interferometer }\end{array}$ \\
\hline $\begin{array}{l}\text { EUTP } \\
\text { Cable Tester }\end{array}$ & Microtest & PentaScanner & Multifunction tester \\
\hline
\end{tabular}


EUTP cable can act as an antenna for electronic noise from such sources as fluorescent lighting, motors, broadcast equipment, and microwaves. EUTP cabling should not be installed near these devices.

\section{Line Mapper}

Line mappers (or end-to-end connectivity testers) verify the link connectivity for each conductor in EUTP cable. A line mapper uses a loopback terminator to verify proper termination. Advanced units also detect open and shorted circuits and provide conductor status printouts.

\section{High-Frequency Signal Generator}

A high-frequency signal generator simulates the live conditions of a fully loaded network. A stable, preset signal source is needed to accurately measure attenuation and crosstalk. A square wave output is needed to accurately simulate network data traffic, but a sine wave output can produce an effect adequate for obtaining characteristic cable performance measurements.

\section{Capacitance Meter}

A capacitance meter tests for conductor damage. It compares measured capacitance on an open-ended cable pair with factory-specified nominal values or accepted industry-standard EIA/TIA 568A values. A pair's mutual capacitance will change if it has been overstressed during installation.

\section{Power Meter}

The power meter receives input from the high-frequency signal generator. It measures the strength of the received signal at the far end of a pair. When the received signal strength is compared to the source strength, the transmitted power loss (attenuation) can be calculated. Nearend crosstalk may also be measured by attaching the signal generator and the power meter to the same end of different pairs.

\section{Multifunction Test Sets}

Modern technology has recently combined all of the required EUTP test equipment into a single hand-held unit. Sandia recommends that the EUTP cabling tests be performed with a mul- tifunction hand-held test set for several reasons:

- Individual test equipment pieces would cost approximately three to four times the cost of a single hand-held multifunction unit.

- Hand-held test sets are conveniently portable and easy to manipulate.

- Hand-held test sets provide one-button multifunction autotesting and simple pass/fail results which reduce testing time and human errors.

- Hand-held test sets can provide advanced features such as internal storage of many test results, variable printout options, and direct test data downloading into computer databases.

- Hand-held test sets can have all test functions calibrated simultaneously by a single manufacturer.

The Sandia-preferred hand-held EUTP multifunction test set is identified in Table 1 . If a testing contractor chooses to substitute different test equipment from those contained in Table 1 , a submittal must be accompanied by appropriate technical data allowing Sandia Department13917 to ascertain equivalence, superiority, or inferiority. In any case, Sandia Department 13917 must approve all test equipment used by testing contractors in fulfilling a termination contract. Sandia additionally requires the testing contractor to record all downloadable software revisions in the Outlet Cable Test Form, Equipment Used section.

All test equipment must be calibrated and certified to be in good working condition in accordance with the equipment manufacturers' recommendations.

\section{EUTP Test Procedures}

\section{Background}

Studies have shown that poor cable and connector installation practices can drastically degrade cabling performance. While cabling problems may currently account for 70 percent of all local area network problems, these cabling problems can be largely eliminated through proper cable installation and testing techniques. Expensive network downtime can be avoided and maintenance costs dramatically reduced 
when a cable infrastructure is properly installed and tested.

The test procedures for EUTP cabling are similar in complexity to those for optical fiber cabling. EUTP cabling tests are far more sensitive than typical telephone cabling tests. EUTP must be more carefully installed and more rigorously tested to ensure its ability to transmit high bitrates. Terminations and connections must be made in accordance with the cable and connector manufacturer's specifications. For example, the wire pairs cannot be untwisted more than $1 / 2$ inch at the points of termination or crosstalk data errors will occur. All personnel involved in EUTP cable installation, termination, or connecting activities at Sandia must be fully aware of the hardware manufacturer's installation requirements and Sandia-required EUTP test procedures.

End-to-end or link testing must be measured after both ends of a cable have been connectorized and mounted in outlets, panels, or frames. This should represent the cable's final physical configuration. At this point, the Sandia required tests must be performed and the test information recorded for progress report submittals or the final test report. Loss and interference values will encompass the sum of the link effects, including contributing factors from both the cable and the connectors. Cables and/or connector assemblies which do not test within Sandia's required test values will be rejected. Cables and/or connector assemblies must be replaced and tested until acceptance. Each EUTP cable test is intended to have a simple pass or fail result as shown on the Outlet Cable Test Form included at the end of this report.

\section{Pretest Training}

EUTP cable termination (with an RJ45 modular jack on one end and a 110 termination frame on the other) involves relatively new and complex assembly procedures. Training facilities, typically operated by EUTP component manufacturers, offer certification for specific EUTP products. All personnel involved in EUTP termination activities at Sandia must be certified by training facilities approved by Sandia Department 13917.

\section{Outlet Cable Test Form}

An Outlet Cable Test Form for recording cable lengths, test data, and calculation results is included at the end of this document. This form is available in hardcopy or electronic (EXCEL spreadsheet) format from Sandia Department 13917.

\section{Daily Test Equipment Preparation}

EUTP cable test equipment must be properly configured each day before testing begins. The following five checks must be made:

- Verify that the test set is still within its manufacturer's calibration warranty period.

- Verify that the test set is set to auto test, and the proper cable type is selected, e.g., Category 5 .

- Verify that the test set's selected NVP matches the cable being tested. AT\&T specifies an NVP value of 0.70 for their four-pair $1061 \mathrm{C}$ riser cable, and 0.75 for their four-pair $2061 \mathrm{~B}$ plenum cable.

- Perform a test set self-test to confirm proper functionality.

- Connect the test set to its matched "smart" terminator (via the test set manufacturer's test cable), and perform an auto test to confirm that the test set and terminator are functioning properly together.

After a successful series of these daily equipment checks, actual cable testing can begin. Modern test sets are capable of performing all of these daily preparations in a single test cycle. Any failures or anomalies must be recorded in the Misc. Notes section of the Outlet Cable Test Form.

Sandia requires the testing contractor to execute the following tests.

\section{Test \#1 - Line Mapping (End-to-End Connec- tivity)}

A cable test set is connected to one end of the cable to be tested, and its terminator (commonly referred to as intelligent, smart, or remote) is connected to the other end of the cable. All four pairs are then checked for proper wiring configuration: open conductors, shorted conductors, crossed pairs, and reversed pairs. The re- 
sults of these tests are recorded as either pass or fail for each pair. Failures require repair or replacement as necessary and retesting until passing results are achieved.

Test \#2 - Loop Resistance (DC - Steady State)

An ohmmeter is connected across one end of a cable pair, with a shorting terminator across the other end of the cable pair. The steady-state DC resistance is measured in ohms and compared to the cable manufacturer's standard values. The permitted values and measured values will increase with longer segments of cable. The test equipment reports the ohms resistance value for recording. Values greater than the allowable resistance are considered fail. Values smaller than the allowable resistance will pass. The result of this test is recorded as either pass or fail. Failures require repair or replacement and retesting until passing results are achieved.

\section{Test \#3 - Attenuation}

Attenuation is measured by transmitting several signals at increasing frequencies across each conductor. The strength of the received signal is compared to the strength of the transmitted signal. The test set may physically measure millivolt signal loss, but should report the loss in units of decibels (dB). The signal loss will normally increase at higher frequencies. The test frequencies and permitted $\mathrm{dB}$ loss values at each tested frequency will be as specified in EIA/TIA 568A Category 5 attenuation specifications for UTP cable. The results of the test will be pass or fail. Failures require repair or replacement and retesting until passing results are achieved.

\section{Test \#4 - Cable Length}

Cable length must be recorded from either the length markings on the cable jacket or from a TDR (or a hand-held multifunction test set incorporating TDR circuitry). Cable-length markings are in feet and must be recorded on the Outlet Cable Test Form. Cables longer than 295 feet ( 90 meters) must be noted because these cables may have data-transfer limitations.

\section{Test \#5 - Capacitance}

When an EUTP cable is damaged, stretched, or improperly terminated, its mutual capaci- tance will change. Each twisted pair is tested with a capacitance meter. The opposite end of the pair being tested is open circuit. The capacitance between each wire pair (mutual capacitance) is measured and recorded in nanofarads (nf). The measured capacitance is then divided by the cable length to obtain the capacitance per foot (nf/ft). EIA/TIA 568A limits the maximum mutual capacitance of Category 5 UTP cable to $5.6 \mathrm{nf} / 328 \mathrm{ft}$. Properly installed EUTP cabling should yield capacitance test results within 2 percent of the cable manufacturer's specification. The result of this test is pass or fail. An occurrence of a pair with mutual capacitance levels greater than EIA/TIA 568A allows is recorded as a failure. Failures require repair or replacement and retesting until passing results are achieved.

\section{Test \#6 and \#7- Near-End Crosstalk (NEXT)}

Near-end crosstalk (NEXT) is the tendency for signals travelling in one pair of wires to be induced into an adjacent wire pair. This crosstalk effect is greatest at the transmission end connection points where the pairs are untwisted and in close proximity. Far-end crosstalk contributions are negligible. NEXT must therefore be measured from both the outlet and the distribution room ends of the link. The worst pair NEXT must be measured in $\mathrm{dB}$. A source must be connected to one pair while adjacent pairs are tested. Impedance-matched terminators (100 ohms) should be used. The test frequencies and permitted worst-pair $\mathrm{dB}$ crosstalk values at each tested frequency will be as specified in EIA/TIA 568A for Category 5 UTP cable. Again, NEXT tests must be performed from both ends of the cable, because this is a "near-end" phenomenon. The results of the test will be pass or fail. Failures require repair or replacement and retesting until passing results are achieved.

\section{Additional Testing}

The following additional tests may be useful for troubleshooting but are not required for cable certification when the above seven tests have passed.

\section{Electrical Noise (EMI/RFI) Test}

Electrical noise is caused by random stray voltages induced into the data transmission ca- 
bling. There are two types of electrical noise tests: impulse noise and average noise.

Impulse Noise - The impulse noise test requires a voltmeter or oscilloscope to monitor each cable pair for more than 10 seconds and record any induced voltage surges or spikes with a duration of 20 nanoseconds or greater. IEEE 802.3 10BaseT specifications define unacceptable impulse noise conditions as more than two occurrences of voltage greater than 264 millivolts within a continuous 10 -second monitored time window. The result of this test is recorded as either pass or fail. Failures should be documented on the Outlet Cable Test Form, Misc. Notes section.

Average Noise - The average noise test is made with a wideband AC noise meter. The intent is to detect and identify EMI/RFI on the EUTP lines. The cable being tested is terminated with its characteristic impedance (typically $100 \mathrm{ohms}$ ) and examined for EMI/RFI in three frequency bands:

- $0 \mathrm{~Hz}$ to $150 \mathrm{KHz}$ (typical sources - $\mathrm{AC}$ power lines, intercoms, telephones, blower motors, elevator equipment)

- $150 \mathrm{KHz}$ to $20 \mathrm{MHz}$ (typical sources - light dimmers, medical equipment, computers, copiers, laser printers)

- $20 \mathrm{MHz}$ to $1 \mathrm{GHz}$ (typical sources - radios, cellular phones, TVs, microwave ovens, broadcast equipment)

The result of this test is pass or fail. An occurrence of root-mean-square noise levels greater than 100 millivolts in any of these three frequency bands is recorded as a failure. Failures should be documented on the Outlet Cable Test Form, Misc. Notes section.

\section{Cable Impedance Test (dynamic)}

Impedance is the combined result from the dynamic effects of resistance, inductance, and capacitance. A cable's impedance will vary at different frequencies of data transmission. Cable manufacturers will list a nominal (average) impedance for their UTP cable at a specific frequency, for example, $100 \mathrm{ohms}$ at $10 \mathrm{MHz}$. Each cable's absolute impedance can be measured via TDR technology at critical frequencies and appropriate incremental steps of frequency change. Each measured impedance will be examined and averaged along the length of the cable. For example, the sweep frequencies should be from 500 $\mathrm{KHz}$ through $100 \mathrm{MHz}$ at incremental steps of $500 \mathrm{KHz}$. The results of the test will be pass or fail. The average measured impedance values at each test frequency must be within 15 percent of the manufacturer's specified values at each test frequency to pass. For example, a specified 100 ohms would pass if measured within 85 to 115 ohms. Note that split pairs may exhibit 20 to 30 ohms impedance fluctuation, which will result in test failure. Failures should be documented on the Outlet Cable Test Form, Misc. Notes section.

\section{Signal-to-Noise Ratio (SNR) Test}

The SNR is the mathematical value in $\mathrm{dB}$ of worst-case NEXT minus worst-case attenuation measured at the same test frequency. The results of the test will be pass or fail. Failures should be documented on the Outlet Cable Test Form, Misc. Notes section. Ideally, a passing NEXT and a passing attenuation should generate a passing SNR.

\section{Progress Reports}

The testing contractor shall submit the following progress reports:

The testing contractor shall submit one copy of all the completed Outlet Cable Test Forms to Sandia Department 13917 on a weekly basis. The testing contractor shall retain the original Outlet Cable Test Forms for inclusion in the final test report.

The testing contractor shall make a total of four weekly submittals which shall include the first four weeks of testing results recorded on Outlet Cable Test Forms.

The weekly submittals shall begin one week after termination begins. The intent is to maximize good termination procedures and isolate any termination problems by studying test results early in the termination process.

The weekly submittals shall be grouped by the name of the terminating person.

The weekly submittals shall include the terminator's name and company in the Misc. Notes section.

Submittals shall be due by 4:00 PM on each 
Friday, and shall include the results from tests performed since the time of the previous submittal (approximately one week).

\section{Final EUTP Test Report}

A final test report which confirms that the EUTP cabling infrastructure has been tested utilizing the procedures contained within this document must be delivered to Sandia Department 13917 within two weeks after completion of the installation. The report must include required EUTP cable test data and other required information for all installed cables. The testing contractor must use the Outlet Cable Test Form included at the end of this document.

The testing contractor must submit three copies of the test report. Each report copy will be labeled and submitted in white, 2-inch threering viewbinders. Each report copy will include

- All completed Outlet Cable Test Forms as described above, bound in order by room number.

- An installer-signed statement of compliance with SAND93-1076 Revised.

- Copies of all certificates of EUTP test equipment calibration/certification.

- Copies of all certificates of training for test personnel.

- Copies of any other information as needed to document the testing of the cable infrastructure.

- A written statement ensuring EUTP performance for the entire installation for a period of 15 years starting from the day of acceptance. 


\section{Optical Fiber}

\section{Background}

During the past 20 years, a tremendous amount of research and design effort has been directed toward developing lightwave transmission. Lightwave transmission is based upon the physical principle of total internal reflection of light. An essential component of lightwave transmission is the actual lightguide, commonly referred to as an "optical fiber." Today's popular uses of optical fiber as a transmission media include voice, data, and video applications. Optical fibers offer many communication advantages such as immunity to external electromagnetic fields, minimization of signal coupling between adjacent conductors, the capability of withstanding caustic atmospheric environments, and most importantly, the propagation of very high bitrate transmissions across long distances.

\section{Optical Fiber Components}

Optical fiber components utilized at Sandia National Laboratories include optical fiber cables, connectors, couplers, buildouts, attenuators, termination panels, outlets, cross-connect jumpers, and splices. These components are further described and specified in SAND93-0002 Revised, Intra-Building Telecommunications Cabling Standard for Sandia National Laboratories. This document can be obtained by contacting Sandia Department 13917.

AT\&T has been, and continues to be, the world leader in optical fiber technology. The efforts of the engineers and scientists at AT\&T Bell Laboratories have traditionally led the optical fiber industry in state-of-the-art products and standardization initiatives. AT\&T optical fiber product capabilities, along with compatibility and standardization, are the basis for Sandia's AT\&T optical fiber component sole-make requirement. Additionally, these products, when installed by an AT\&T certified VAR, are warranted for a period of 15 years.

The following are general descriptions of each optical fiber component.

\section{Optical Fiber Cables}

An optical fiber is a cylindrically shaped light waveguide. Today, high bit-rate transmission optical fibers are typically composed of silicon cladding and doped silicon core. Optical fibers have evolved into two basic types, Multimode and Singlemode. These types of optical fibers have been incorporated within many national standards such as 10BaseF and FDDI. Newly developing standards such as Fiber Channel, ESCON, SONET and A'TM will also incorporate them.

All optical fiber intrabuilding cabling at Sandia must be AT\&T lightguide building cable to provide maximum capability, compatibility, and reliability for years to come.

\section{Optical Fiber Connectors, Couplers, Build- outs, and Attenuators}

Optical fiber connectors, couplers, buildouts, and attenuators are used to terminate optical fibers and must match the optical fiber transmission capabilities. Sandia standardized on the AT\&T ST ${ }^{\circledR}$ components for both Multimode and Singlemode applications in 1989. AT\&T developed and patented the ST ${ }^{\circledR}$ optical fiber components. Multimode and Singlemode ST® components differ primarily in dimensional tolerances. Singlemode components require more precise tolerances that result in associated higher costs. ST® components have been adopted by many national standards committees.

All optical fiber connectors, couplers, buildouts and attenuators at Sandia must be AT\&T $\mathrm{ST} \circledast$ components.

\section{Optical Fiber Termination Panels, Outlets, and Cross-Connect Jumpers}

There are two types of optical fiber termination panels used at Sandia National Laboratories for intrabuilding cabling, the IDR wallmount panel, and the Technical Control Center (TCC) rack mount panel. Both of these optical fiber termination panels are shown in SAND93-0002 Revised.

IDR optical fiber termination panels house 24 terminated optical fibers and are designed to mount vertically on wall surfaces. Each IDR is designed to service hundreds of users. As a result, thousands of optical fibers must be terminated in the IDR. The walls of the IDR are an 
excellent place for termination panels and passive cross-connections. All IDR optical fiber termination panels at Sandia must be AT\&T lightguide interconnection unit components.

TCC optical fiber termination panels house 72 terminated optical fibers and are designed to be rack mounted in equipment bays. TCCs are designed for and populated with high-dollar electronic switching equipment and network routers. This equipment is typically mounted in 19or 23-inch equipment bays. Some of these equipment bays are allocated for optical fiber termination and contain the rack-mounted optical fiber termination panels. All TCC optical fiber termination panels at Sandia must be AT\&T lightguide shelf termination components.

Sandia's standard outlet is shown in SAND93-0002 Revised. The outlet is commonly referred to as a multimedia outlet because it houses both EUTP and optical fiber cables. AT\&T's original $40 \mathrm{~A} 1$ outlet was specifically modified to accommodate Sandia's standard cable suite and red and black color requirements. All outlets at Sandia must be AT\&T 40A1 components.

Cross-connect jumpers must be composed of optical fiber and connectors that match the intrabuilding cabling components to extend the link capabilities. All optical fiber cross-connect jumpers at Sandia must be assembled with AT\&T optical fiber cable and AT\&T ST ${ }^{\circledR}$ connectors.

\section{Optical Fiber Splices}

At Sandia, mechanical optical fiber splices have been used for cable-cut emergency restoration. Fusion splicing has been used to minimize optical reflectivity and loss in the Labwide Singlemode interbuilding backbone which is now complete.

Splicing is not permitted in any intrabuilding cabling and will not be discussed in this document due to its limited application. Any cabling issues concerning splicing must be brought to the attention of Sandia Department 13917 personnel for consideration and approval.

\section{Optical Fiber Test Equipment}

There are four basic types of optical fiber test equipment used to verify installed optical link transmission capabilities:

- optical loss/return loss test set

- optical time domain reflectometer (OTDR)

- optical interferometer

- optical frequency spectrum analyzer.

\section{Optical Loss/Return Loss Test Set}

An optical loss test set (commonly referred to as an attenuation meter) contains both an optical source and an optical power meter in one instrument. Optical loss test sets with dual wavelength attenuation testing capabilities (and optical return loss testing capabilities for Singlemode) are required at Sandia for testing of individual optical links.

Optical attenuation is one of the most important transmission limitation factors for both Multimode and Singlemode components. An optical source injects a constant-wave frequency of light into an optical link. The power meter displays the amount of light received after propagating the optical link. The amount of light received is compared to the amount of light injected. The difference (minus the interconnection jumper losses) represents optical attenuation. It is most often expressed as power loss in units of dBs. It can also be expressed in units of milliWatts ( $\mathrm{mWs}$ ). The accuracy of the results is dependant on source and meter circuitry tolerances and operational procedures. Proper operational procedures, including frequent referencing and high-quality equipment, can yield accurate, repeatable, power-loss measurements. At Sandia, optical loss test sets are required to measure link attenuation (LA). LA is defined as the cumulative optical power loss of all optical events contained within an entire optical link.

Optical reflections are an additional critical transmission parameter, especially for Singlemode components. Optical reflections cause detrimental effects including mode hopping, multiple path interference (jitter), and output power fluctuations. Large reflections typically result in in- 
creased receiver bit-error rates in digital systems and increased signal-to-noise ratios in analog systems. At Sandia, optical return loss test sets are required to measure link return loss (LRL). LRL is defined as the cumulative optical power return loss of all optical reflections contained within an optical fiber link.

Accurate LA and LRL measurements are required to form Sandia's optical link baseline. From these optical link baselines, optical transmitter and receiver performances can be predicted and prescribed in current and future circuit design efforts.

\section{Optical Time Domain Reflectometer (OTDR)}

Optical time domain reflectometers (OTDR) can measure optical fiber and event loss, as well as fiber length. OTDRs contain both an optical source and a receiver. The ability to operate this device by a single person from one end of the optical link is an inherent advantage. OTDRs are excellent for immediate assessment of connector or splice quality. They are indispensable when troubleshooting optical links. Loss events (broken fibers, crashed/dirty connectors, etc.) can be located within inches or feet of their occurrence.

\section{Optical Interferometer}

Optical interferometers allow an unparalleled visual inspection of an optical connector face with a highly magnified three-dimensional view (spectrograph) displayed on a video monitor. A three-dimensional view is achieved by superimposing incremental depth lines (or fringes) on a two dimensional connector face front-view. Concentric equidistant circular depth lines represent a perfectly domed connector face. Precise coupling of two perfectly domed connectors will place the optical fiber cores in contact resulting in optimal alignment. This connector alignment minimizes both loss and return loss values.

\section{Optical Frequency Spectrum Analyzer}

At Sandia, frequency spectrum analysis of an optical link is not required. The high-quality optical components required by Sandia bring with them guaranteed bandwidth specifications as stated by published manufacturing test results.
NOTE: The Sandia preferred optical loss/ return loss test sets, OTDR, and optical interferometer are identified in Table 1. If a testing contractor chooses to substitute different test equipment from those contained in Table 1, a submittal must be accompanied by appropriate technical data allowing Sandia Department 13917 to ascertain equivalence, superiority, or inferiority. In any case, Sandia Department 13917 must approve all test equipment used by testing contractors in fulfilling a termination contract. Sandia additionally requires the testing contractor to record all downloadable software revisions in the Outlet Cable Test Form, Equipment Used section.

All test equipment must be calibrated and certified in good working condition in accordance with the equipment manufacturers' recommendations.

\section{Optical Fiber Test Procedures}

\section{Pretest Training}

Direct connectorization (assembling a connector onto the end of an optical fiber) involves many complex assembly procedures. Training facilities, typically operated by optical component manufacturers, offer certification for specific optical products. All personnel involved in optical connectorization activities at Sandia must be certified by training facilities approved by Sandia Department 13917.

\section{Outlet Cable Test Form}

The Outlet Cable Test Form for recording cable lengths, test data, and calculation results is included at the end of this document. This form is available in hardcopy or electronic format (EXCEL spreadsheet) from Sandia Department 13917.

\section{Optical Fiber Cable Length Measurement}

Cable length must be recorded from either the length markings on the cable jacket or from OTDR measurements. Cable lengths must be recorded in feet on Outlet Cable Test Forms. 
Optical Fiber Test Equipment Setup

All optical fiber test equipment must be properly adjusted prior to use. The user must follow the detailed setup instructions in the equipment instruction manual(s). The variable unit adjustments on the test equipment must be calibrated to match the cable manufacturer's stated cable transmission parameters. For example, OTDR setup requirements include setting the cable's group index of refraction, $\mathrm{N}_{\mathrm{g}}$, as defined by the cable manufacturer.

The group index of refraction is a complex value based upon several optical cable properties: the test wavelength, refractive index profile, modal conditions (in Multimode fiber), and fiber length.

Typical values of $\mathrm{N}_{\mathrm{g}}$ in silicon optical fibers range from 1.46 for Singlemode to 1.49 for Multimode.

\section{Optical Fiber Connector Validation Test}

As each optical fiber connector assembly is completed, a $400 \mathrm{X}$ visual inspection (and a loss test set or OTDR measurement when necessary) must be made to assess immediate acceptance or rejection of the connector assembly. The connector assembly will be rejected if any visible imperfection penetrates the core of the fiber, the connector loss displayed by the Loss Test Set or OTDR causes the link attenuation to exceed Sandia's acceptable LA, or the connector reflectance causes the link return loss to exceed Sandia's acceptable LRL. Rejected connector assemblies must be replaced and tested until Sandia acceptable measurements are obtained.

\section{Optical Reference Level Measurement}

An optical source must be connected to a power meter with a short (2-3 meter) jumper cable. The jumper cable must have identical transmission characteristics as the optical link being measured. Operational stabilization (primarily ambient thermal conditions) must be reached by the optical sources prior to any measurements. After stabilization, the received optical power levels in $\mathrm{dBm}$ must be recorded. Sandia recommends that this procedure be repeated frequently during the measurement process to verify the integrity of optical fiber test jumpers and the optical source. The optical source and power meter serial numbers of the units used for testing must be recorded on each Outlet Cable Test Form in the Test Equipment section.

\section{Optical Link Attenuation (LA) Measurement}

Optical LA must be measured after both ends of an optical fiber have been connectorized, dressed and mounted in outlets or panels. This should represent a fiber's final physical configuration. At this point, the link attenuation must be measured and recorded with optical sources and power meters.

A source must be connected to one end (A) of the optical link to be measured, and a power meter connected to the other end (B). The received power level (A to $B$ ) must be recorded in $\mathrm{dB}$ for each wavelength. The locations of the source and power meter must then be reversed. The received power level ( $\mathrm{B}$ to $\mathrm{A}$ ) must be recorded in $\mathrm{dB}$ for each wavelength. The two recorded power levels for each wavelength must then be averaged and recorded in $\mathrm{dB}$.

Most modern attenuation test sets incorporate circuitry which automatically subtracts a stored reference level from the displayed loss readings. In this case, the optional reference levels on the Outlet Cable Test Form may remain empty.

If test equipment is used that does not incorporate this automatic calibration or "zeroing" feature, then the reference levels must be measured and recorded in the optional reference levels on the Outlet Cable Test Form, manually subtracted from the (A to $B)(B$ to $A$ ) averages, and then recorded as the $L A$ averages in $\mathrm{dB}$.

The appropriate procedure above must be repeated for all optical links. All of the measured and calculated values must be recorded on the Outlet Cable Test Form.

\section{Optical Link Return Loss (LRL) Measurement}

Optical LRL must be measured and recorded for all Singlemode optical links. Sandia requires a constant-wave laser source for all LRL measurements, because the "light on" optical signal most closely represents maximum link data transmission independent of protocols or encoding schemes. An OTDR can yield accurate and repeatable $\mathrm{LRL}$ data but requires extensive knowledge and manipulation of variable param- 
eters such as pulse width and wavelength. Varying these parameters can have dramatic effects on the resultant data. It is for this reason that Sandia has identified the loss/return loss test sets in Table 1 as the preferred equipment to measure LRL. This must be accomplished by following the (A to $\mathrm{B})(\mathrm{B}$ to $\mathrm{A})$ averaging procedure described in the optical link loss measurement section above. The preferred loss/return loss test set listed in Table 1, utilizes the coupler method of measurement, which is consistent with ANSI EIA/TIA FOTP 107. All of the measured and calculated values must be recorded on the Outlet Cable Test Form.

\section{Optical Link Acceptance Criteria}

The Multimode and Singlemode link attenuation averages and Singlemode link return loss average for each optical fiber link must not exceed Sandia's acceptable optical link attenuation or acceptable optical link return loss as stated below.

\section{Acceptable Optical Link Attenuations -} were calculated with the following formula:

\section{Acceptable Optical Link Attenuation = $(\mathrm{CoQ} \times \mathrm{CoA})+(\mathrm{CaL} \times \mathrm{CaA})$}

where: $\mathrm{CoQ}=$ Connector Quantity

$$
\begin{aligned}
& \mathrm{CoA}=\text { Connector Attenuation in } \mathrm{dB} \\
& \mathrm{CaL}=\text { Cable Length in } \mathrm{km} \\
& \mathrm{CaA}=\text { Cable Attenuation in } \mathrm{dB} / \mathrm{km}
\end{aligned}
$$

The following values are manufacturer published optical component specifications:

CoA for MM ST® II connectors $=0.35 \mathrm{~dB} \pm 0.2$ CoA for SM ST ${ }^{\circledR}$ II connectors $=0.35 \mathrm{~dB} \pm 0.2$ $\mathrm{CaA}$ for $\mathrm{MM}=3.4 \mathrm{~dB} / \mathrm{km} @ 850 \mathrm{~nm}$ $1.0 \mathrm{~dB} / \mathrm{km} @ 1300 \mathrm{~nm}$ $\mathrm{CaA}$ for $\mathrm{SM}=0.4 \mathrm{~dB} / \mathrm{km} @ 1310 \mathrm{~nm}$ $0.3 \mathrm{~dB} / \mathrm{km} @ 1550 \mathrm{~nm}$

Sandia-acceptable LA calculations were derived with worst-case component tolerances. These values represent the upper limit of acceptability. Sandia fully expects typical results to approach manufacturer published statistical averages which are considerably lower.

\section{Acceptable LA for Multimode links}

(300 ft. link with $2 \mathrm{ST} \otimes ~ I I ~ c o n n e c t o r s)$

$=(2 \times 0.55 \mathrm{~dB})+(0.09 \mathrm{~km} \times 3.4 \mathrm{~dB} / \mathrm{km})$

$$
\begin{gathered}
=1.1 \mathrm{~dB}+0.31 \mathrm{~dB} \\
=1.41 \mathrm{~dB} \\
=1.4 \mathrm{~dB} \text { for } 850 \mathrm{~nm} \\
=1.2 \mathrm{~dB} \text { for } 1300 \mathrm{~nm}
\end{gathered}
$$

\section{Acceptable LA for Singlemode links \\ (300 ft. link with 2 STß II connectors) \\ $=(2 \times 0.55 \mathrm{~dB})+(0.09 \mathrm{~km} \times 0.4 \mathrm{~dB} / \mathrm{km})$

$$
\begin{gathered}
=1.1 \mathrm{~dB}+0.04 \mathrm{~dB} \\
=1.14 \mathrm{~dB}
\end{gathered}
$$

\section{$=1.1 \mathrm{~dB}$ for both 1310 and $1550 \mathrm{~nm}$}

Acceptable Optical Link Return Loss - was derived by in-depth studies regarding optical reflection theory, actual test-equipment capabilities, and test procedures.

The following values are manufacturer published specifications:

$$
\begin{aligned}
& \text { ST®II Singlemode Connector } \\
& \text { Return Loss Average }=42 \mathrm{~dB} \\
& \text { Return Loss Max. }=35 \mathrm{~dB} \\
& \\
& \text { Singlemode Cable, } 300 \text { feet } \\
& \text { Return Loss }=\infty \mathrm{dB}
\end{aligned}
$$

(Note: Sandia assumes the intrinsic reflectance contribution of 300 feet of properly installed Singlemode optical fiber to be negligible.)

Sandia-Acceptable LRL calculations were derived with worst-case component tolerances. These values represent the upper limit of acceptability. Sandia fully expects typical results to approach manufacturer published statistical averages which are considerably higher.

\section{Acceptable LRL for Singlemode links (300 ft. link with $2 \mathrm{ST} \circledast$ II connectors) \\ $=35 \mathrm{~dB}$ for both 1310 and $1550 \mathrm{~nm}$}

Any optical fiber link with a link attenuation average or link return loss average exceeding Sandia's acceptable LA average or acceptable LRL average must be treated as unacceptable, and the optical link problem must be identified 
and corrected. The authority to abandon an unacceptable optical link is solely owned by Sandia Department 13917.

\section{Progress Reports}

The testing contractor shall submit progress reports as follows.

The testing contractor shall submit one copy of all the completed Outlet Cable Test Forms to Sandia Department 13917 on a weekly basis. The testing contractor shall retain the original Outlet Cable Test Forms for inclusion in the final test report.

The testing contractor shall make a total of four weekly submittals which shall include the first four weeks of testing results recorded on Outlet Cable Test Forms.

The weekly submittals shall begin one week after termination begins. The intent is to maximize good termination procedures by studying test results early in the termination process.

The weekly submittals shall be grouped by the name of the terminating person.

The weekly submittals shall include the terminator's name and company in the Misc. Notes section.

Submittals shall be due by 4:00 PM on each Friday, and shall include the results from tests performed since the time of the previous submittal (approximately one week).

\section{Final Optical Test Report}

A final optical test report which confirms that the optical cabling infrastructure has been tested utilizing the procedures contained within this document must be delivered to Sandia, Department 13917, within two weeks after completion of the installation. The report must include required optical fiber optic fiber cable-test data, calculated values, and other required information for all installed cables. The testing contractor must use the Outlet Cable Test Form included at the end of this document.

The testing contractor must submit three copies of the final test report.

Each final report copy will be labeled and submitted in white, 2 -inch three-ring view binders. Each final report copy will include:

- All completed Outlet Cable Test Forms as described above, bound in order by room number.

- An installer-signed statement of compliance with SAND93-1076 Revised.

- Copies of all certificates of optical test equipment calibration/certification.

- Copies of all certificates of training for test personnel.

- Copies of any other information as needed to document the testing of the cable infrastructure.

- A written statement assuring optical fiber performance of the entire installation for a period of 15 years starting from the day of acceptance. 
This page intentionally left blank. 
APPENDIX A

Form 


\section{OUTLET CABLE TEST FORM}

\begin{tabular}{|c|c|c|c|c|c|c|c|}
\hline \multirow{2}{*}{\multicolumn{2}{|c|}{$\begin{array}{r}\text { Test Date: } \\
\text { Building Number: } \\
\text { Room Number: }\end{array}$}} & & \multirow{2}{*}{\multicolumn{2}{|c|}{$\begin{array}{r}\text { Test Person's Name: } \\
\text { IDR Name: } \\
\text { Outlet Number: }\end{array}$}} & & \multirow{2}{*}{$\begin{array}{r}\text { Red } \\
\text { Black }\end{array}$} & Outlet Color: \\
\hline & & & & & & & \\
\hline \multicolumn{8}{|c|}{ UTP CABLES } \\
\hline & & & \multicolumn{3}{|c|}{ Voice Block ID: } & Data Block ID: & \\
\hline & $\begin{array}{l}\text { Test \#1 } \\
\text { Line Map }\end{array}$ & $\begin{array}{c}\text { Test \#2 } \\
\text { Loop Plesistance }\end{array}$ & $\begin{array}{c}\text { Test \#3 } \\
\text { Attenuation }\end{array}$ & $\begin{array}{l}\text { Test \#4 } \\
\text { Length }\end{array}$ & $\begin{array}{c}\text { Test \#5 } \\
\text { Capacitance }\end{array}$ & $\begin{array}{c}\text { Test } \# 6 \\
\text { NEXT: IOR to User }\end{array}$ & $\begin{array}{c}\text { Test } \# 7 \\
\text { NEXT: User 10 IDR }\end{array}$ \\
\hline Cable Name & X-pass; O-fail & X-pass; O-fail & X-pass; O-fail & X-pass; O-fail & X-pass; O-fail & $X$-pass; O-fail & X-pass; O-fail \\
\hline & & & & & & & \\
\hline & & & & & & & \\
\hline & & & & & & & \\
\hline
\end{tabular}

\section{MULTIMODE FIBER CABLE}

LU Number:

Cable Name:

Length (feet):

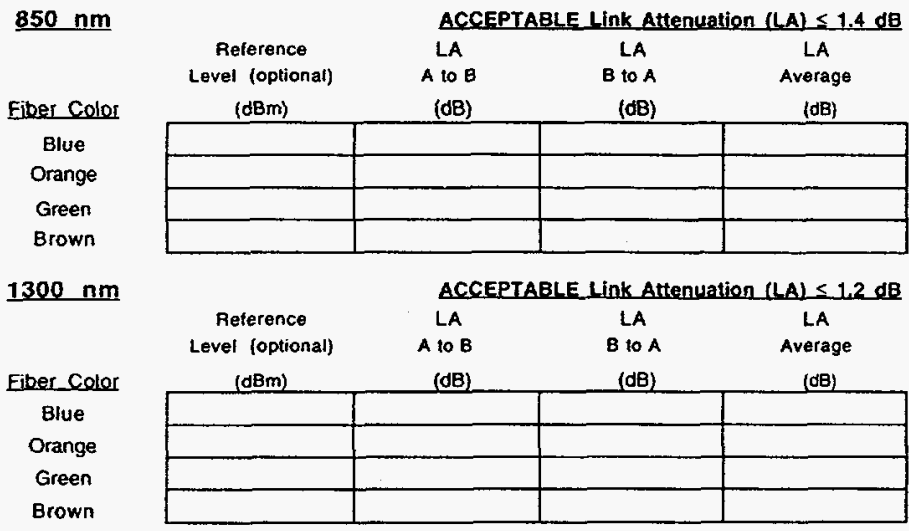

\section{SINGLEMODE FIBER CABLE}

LIU Number

Cable Name: Length (feet):

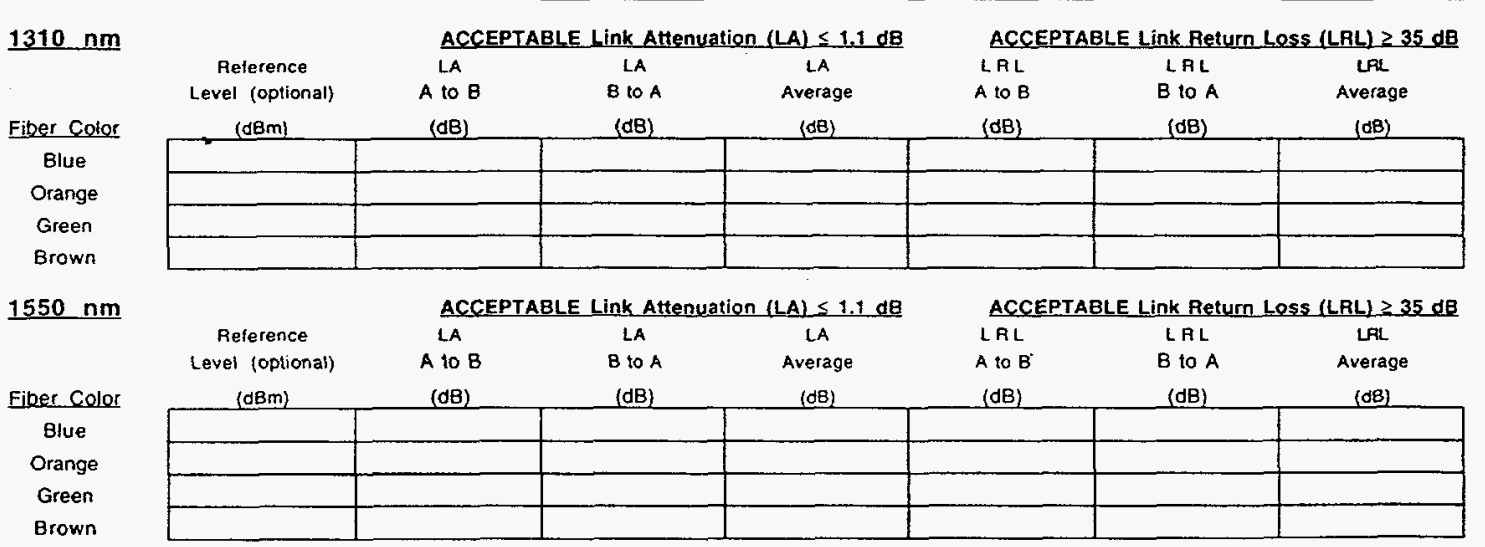

Test Equipment Used: 


\section{DISTRIBUTION}

233 MS0807R. L. Adams, 13917

1 MS9018Central Technical Files, 8523-2

7 MS0899Technical Library, 13414

1 MS0619Technical Publications, 13416

10 MS0100Document Processing, 7613-2 for DOE/OSTI 